\title{
Formulation and evaluation of virgin coconut oil cream for atopic dermatitis prepared using green processing method
}

\author{
Gina C. Castro ${ }^{1,2 *} \mathcal{E}$ Jovencio G. Apostol ${ }^{1-3}$ \\ ${ }^{1}$ The Graduate School; ${ }^{2}$ Faculty of Pharmacy; ${ }^{3}$ Research Center for the Natural and Applied Sciences \\ University of Santo Tomas, 1015 Manila, Philippines
}

\begin{abstract}
A cream formulation for atopic dermatitis, containing virgin coconut oil as non-steroidal active ingredient was developed. Three prototype formulations containing $20 \%$ virgin coconut oil were developed using controlled heating with post-emulsification addition of an emulsifying polymer. The products are white, smooth, soft creams with skin-compatible $\mathrm{pH}$. All samples showed no phase separation or color changes through four cycles of freeze-thaw testing. Effect of elevated temperature $\left(40^{\circ} \mathrm{C}\right)$ within a 6-month period, and of varying UV light intensities within 30 days on the appearance, $\mathrm{pH}$, viscosity, particle size, and creaming index were assessed. The prototype formulations were found to be non-irritating in the Draize rabbit method. The most stable prototype was shown to help improve symptoms associated with atopic dermatitis after 1 week of twice daily application in a preliminary usage test. The virgin coconut oil cream formulated using green method has good potential as a nonsteroid alternative for the management of atopic dermatitis symptoms.
\end{abstract}

Keywords: atopic dermatitis, green method, stability testing, topical cream, virgin coconut oil

\section{INTRODUCTION}

Atopic dermatitis (AD) is a chronic inflammatory skin disorder affecting up to $25 \%$ of children worldwide, and is known to adversely affect the quality of life of patients [1, 2]. The gold standard for the treatment of this disease involves the use of topical corticosteroids, but prolonged use is associated with cutaneous side effects and may even lead to systemic effects like pituitaryadrenal axis suppression and retardation of growth in children [3]. Thus, there is a growing

*To whom correspondence should be addressed: gnacastro2006@gmail.com interest in finding non-steroidal alternatives that are safe and effective for use among AD patients.

Complementary or alternative medicine, such as herbal preparations, has become popular for the treatment of $\mathrm{AD}[4,5]$. A number of natural products have been widely used in Asian countries for AD therapy [6]. Among these is virgin coconut oil (VCO) which is a functional food oil with proven anti-inflammatory activity [7], moisturizing effect [8], and dermal woundhealing property [9]. Clinical trials have shown pure VCO to be effective in treating symptoms of $\mathrm{AD}$ and xerosis [10-12]. 
Emulsions-based products, such as creams, provide the most convenient and versatile dosage format for oil actives. The cream format is highly suitable for topical dermatological applications due to ease of administration, which helps improve patient compliance. Products containing VCO have been prepared using conventional emulsification methods that require exposure to elevated temperatures with high shear [13], or high concentration of surfactants [8]. These processes are known to hasten hydrolysis of VCO with potential loss of activity [14], and can disrupt skin barrier functions [15]. The recent introduction of emulsifying polymers, like Simulgel ${ }^{\mathrm{TM}} \mathrm{NS}$, in cosmetics has allowed the creation of creams without heating, high-energy emulsification, or use of high-dose surfactants [16].

This paper presents a topical cream containing VCO as natural active at concentrations as high as $20 \%$ for skin conditions like AD, using minimal heat emulsification to help preserve vital components responsible for its therapeutic effects. To our knowledge, emulsifying polymers such as Simulgel ${ }^{\mathrm{TM}}$ NS have not yet been applied in topical formulations containing VCO. The use of this polymer enables the green technique of low-heat emulsification.

\section{Materials AND Methods}

Materials. VCO was purchased from Pasciolco Agri Ventures (Philippines). Simulgel ${ }^{\mathrm{TM}}$ NS (Hydroxyethyl acrylate/sodium acryloyldimethyltaurate copolymer and squalane and polysorbate 60) (Seppic) was received as gift sample from Euro Chemicals, Inc. (Philippines) Samples of Olivatis 15 (Olive oil glycereth-8 esters) (Medolla Ltd.), Medsmul SE PF (Glyceryl stearate and ceteareth-20 and ceteareth-12 and cetearyl alcohol and cetyl palmitate) (Medolla Ltd.), Ceteth-6 (Ceteareth-6 and cetearyl alcohol) and TC-Carbomer 340 (Guangzhou Tinci Materials Technology Co., Ltd.) were obtained from Amchem Marketing. Other suitable grade chemicals were purchased from Alyson's Chemical Enterprises, Inc. (Philippines).

Ingredient compatibility screening. Binary mixtures (1:1 mass ratio) of VCO with different emulsion excipients, namely carbomer 340, ceteth-6, cetyl alcohol, citric acid, Medsmul SEPF, Olivatis 15, Simulgel ${ }^{\mathrm{TM}}$ NS, sodium benzoate, and triethanolamine were prepared and stored in sealed glass containers $50 \pm 2^{\circ} \mathrm{C}$ for 3 weeks. Samples stored at $30 \pm 2^{\circ} \mathrm{C}$ served as control. The physical appearance of the mixtures at the start of and after the prescribed storage period were noted. Any significant change in the physical appearance of the mixtures after the storage period indicated incompatibility between VCO and the other ingredient.

Cream preparation. Ingredients found to be compatible with VCO in the screening were used in the development of cream formulations. Four methods were tested for the preparation of a cream based on VCO (20\%) and Simulgel ${ }^{\mathrm{TM}} \mathrm{NS}$ (3\%).

Method 1-Cold processing: Simulgel ${ }^{\mathrm{TM}}$ NS was initially dispersed in water with sodium benzoate and citric acid to form a gel. The oil phase containing VCO and Olivatis-15 was then incorporated into the gel and the mixture gently stirred until homogenous.

Method 2-Hot processing in oil phase: Simulgel ${ }^{\mathrm{TM}}$ NS was heated in an oil phase containing VCO and cetyl alcohol to $50^{\circ} \mathrm{C}$. Water, sodium benzoate and citric acid were heated to $55^{\circ} \mathrm{C}$ in a separate container. The water phase was added to the oil phase with stirring, and the cream was allowed to cool.

Method 3-Hot processing in water phase: Simulgel ${ }^{\mathrm{TM}}$ NS was mixed with water, sodium benzoate and citric acid to form a gel and then heated to $55^{\circ} \mathrm{C}$. In a separate container, VCO and cetyl alcohol were heated to $50^{\circ} \mathrm{C}$. The oil phase was added to the water phase with stirring, and the cream was allowed to cool. 
Method 4-Hot processing with postemulsification addition of Simulgel ${ }^{\mathrm{TM}}$ NS: Water phase was prepared by heating water with sodium benzoate and citric acid to $55^{\circ} \mathrm{C}$. VCO and cetyl alcohol were heated to $50^{\circ} \mathrm{C}$ in a separate container. The oil phase was added to the water phase with stirring. Simulgel ${ }^{\mathrm{TM}} \mathrm{NS}$ was incorporated during emulsification with continuous mixing until homogenous, and the cream allowed to cool with very occasional mixing.

Cream formulation. Based on the smooth texture of the final product and the ease of scaleup applications, Method 4 was adapted for subsequent formulation activities. Different concentrations of secondary emulsifiers, such as Olivatis-15, Medmul SEPF and Ceteth-6, were incorporated (Table 1).

The cream formulations were initially evaluated based on the following parameters: (a) physical appearance: color, odor, texture, and consistency; (b) pH: skin-compatible range of 5-6.5, and (c) centrifuge test: no phase separation at $3000 \mathrm{rpm}$ for $30 \mathrm{~min}$ [8].

Accelerated stability testing. Prototype formulations that were found to be satisfactory in terms of physical appearance, $\mathrm{pH}$, centrifuge test were further assessed through freeze-thaw test, elevated temperature test, photostability test, and skin irritation testing to determine the

Table 1. Formula composition of virgin coconut oil creams

\begin{tabular}{l|c|c|c|c|c}
\hline \multirow{2}{*}{ Raw Materials } & \multicolumn{5}{|c}{ \% Weight by weight } \\
\cline { 2 - 6 } & $F 1$ & $F 2$ & $F 3$ & $F 4$ & $F 5$ \\
\hline A. Virgin coconut oil & 20.00 & 20.00 & 20.00 & 20.00 & 20.00 \\
\hline Cetyl alcohol & 3.00 & 3.00 & 3.00 & 3.00 & 3.00 \\
\hline Olivatis-15 & 1.50 & 1.00 & - & - & - \\
\hline Medsmul SE PF & - & & 2.00 & 1.00 & - \\
\hline Ceteth-6 & - & & - & - & 1.00 \\
\hline B. Citric acid & 0.05 & 0.05 & 0.05 & 0.05 & 0.05 \\
\hline Sodium benzoate & 0.20 & 0.20 & 0.20 & 0.20 & 0.20 \\
\hline Water & q.s. & q.s. & q.s. & q.s. & q.s. \\
\hline C. Simulgel $^{\text {TM }}$ NS & 3.00 & 3.00 & 3.00 & 3.00 & 3.00 \\
\hline
\end{tabular}

most stable and safe formulation for preliminary clinical evaluation.

Freeze-Thaw test: Four cycles of freeze-thaw test were additionally performed following the method of Korac and associates with minor modifications [17]. Sample formulations were filled into suitable glass containers. For each cycle, the following steps were followed: (1) samples were placed in a refrigerator at $-10^{\circ} \mathrm{C}$ for $24 \mathrm{~h}$; (2) samples were left at room temperature for $24 \mathrm{~h}$ to thaw; (3) samples were placed in a thermostatic chamber at $40^{\circ} \mathrm{C}$ for 24 h; and (4) samples were allowed to equilibrate at room temperature for $24 \mathrm{~h}$. The properties of the samples were assessed before the freeze-thaw process and after every cycle until the fourth cycle. Sample formulations kept at $30^{\circ} \mathrm{C}$ served as control. Color changes and phase separation were interpreted as instability.

Elevated temperature test: Samples of the three prototype cream formulations were placed in flint glass bottles with plastic screw caps and stored in a stability oven maintained at $40 \pm 2^{\circ} \mathrm{C}$ for a period of 6 months [18]. Comparable samples stored at $30 \pm 2^{\circ} \mathrm{C}$ served as control. The following physicochemical properties of the prototype formulations were evaluated at time $0,1,3$, and 6 months:

- Organoleptic properties

- $\mathrm{pH}$ value, based on three independent $\mathrm{pH}$ measurements

- Viscosity, measured in triplicates using Brookefield DV-II + PRO Viscometer (spindle no. 6 at $50 \mathrm{rpm}$ ) after $30 \mathrm{sec}$ from start of spindle rotation.

- Particle sizes, determined using a previously reported method with slight modification [19]. A small portion of each sample was treated with few drops of $1 \%$ Amaranth dye solution, placed on a microscope slide, and viewed through an 
Olympus CX21 microscope using a magnification of $1000^{\prime}$ at room temperature. The mean area $\left(\mu \mathrm{m}^{2}\right)$ of the emulsion oil droplets were calculated on the basis of 15 droplets using Image $\mathrm{J}$ app. Three independent measurements were performed.

- Creaming Index, determined using the method of Winuprasith and Suphantharika [20]. Prototype formulations were transferred into individual transparent bottles and sealed with plastic caps. The samples were kept at room temperature and the movement of any creaming boundary were noted. The height of the total emulsion in the bottle $\left(\mathrm{H}_{\mathrm{T}}\right)$ and the height of the serum layer $\left(\mathrm{H}_{\mathrm{S}}\right)$ were measured. Degree of creaming was defined by the Creaming Index $\left(\mathrm{C}_{\mathrm{I}}\right)$ as ratio of $\mathrm{H}_{\mathrm{S}}$ and $\mathrm{H}_{\mathrm{T}}$ multiplied by 100 .

Photostability test: Samples of selected prototype formulations were placed in sealed transparent bottles and kept in an illuminating cabinet provided with 60 -watt fluorescent bulb for 30 days [21]. Containers were positioned at the following distances from the light source: 1 foot (60 candle power), 2 feet ( 15 candle power), and 3 feet (6.7 candle power). Samples of prototype formulations kept in a wooden stock cabinet served as control. Physicochemical properties of the prototype formulations were evaluated at the end of the illumination period.

Skin irritation test. Irritation potential of the prototype formulations was determined using the Draize rabbit method [22]. Experimental protocol was approved by the University of Santo Tomas - Institutional Animal Care and Use Committee (IACUC) (Code No. RC2015550229) with Bureau of Animal Industry (BAI) Animal Research Permit No. AR-2016-352. The Primary Irritation Index (PII) was estimated by getting the average of the score for erythema and edema for the abraded and unabraded sites in test animals for each group.
Preliminary usage test. The most stable and non-irritating prototype formulation was subjected to preliminary usage test among pediatric patients with AD. Clinical protocol, patterned after the study of Padilla-Evangelista and colleagues [10], was approved by the University of Santo Tomas Graduate School Ethics Review Committee. Four patients, aged two to 18 , with $\mathrm{AD}$ were recruited and assessed based on the severity scoring for AD (SCORAD) index at baseline and after one week of twice daily applications of the formulated $20 \%$ VCO cream. Signed and dated written informed consent were obtained from the parents. Objective SCORAD (represented by total surface with eczema, and intensity items like erythema, edema, oozing, excoriation, lichenification, and dryness), and subjective SCORAD (pruritus and sleep loss) indices at baseline and post-treatment were assessed by study dermatologist. Incidences of adverse events were also documented.

\section{Results AND DisCUSSION}

Ingredient compatibility screening. VCO at a concentration of $20 \% \mathrm{w} / \mathrm{w}$, served as natural anti-inflammatory and moisturizing active ingredient in the products. The ideal VCO formulation should be prepared without heating beyond $60^{\circ} \mathrm{C}$ (the upper temperature limit to which VCO is exposed during extraction) to minimize hydrolysis [23], and should not contain irritating substances to make it suitable for use in various diseased skin conditions like $\mathrm{AD}$, where the pure oil has been proven to be effective.

An emulsifying polymer, such as Simulgel ${ }^{\mathrm{TM}}$ NS, was used as gelling and thickening agents to create creams without heating or high-energy emulsification [16]. These are pre-neutralized polymers based on hydro-swelling droplets that consist of oil, acrylate-acrylamide polymer, water, and surfactant. 
Excipients were incorporated to allow the formulation of VCO using minimal-heat emulsification. The excipients are either liquid at room temperature or solid melting at $50^{\circ} \mathrm{C}$. Carbomer 340 is a thickening agent that requires $\mathrm{pH}$ adjustment with neutralizing agents like triethanolamine. Cetyl alcohol is a viscosity modifier that also functions as emollient and emulsifier. Olivatis-15, Medsmul SEPF, and ceteth-6 are commonly used as co-emulsifiers in cosmetic products. Sodium benzoate is a water-soluble preservative, and citric acid is a $\mathrm{pH}$ adjuster.

There was no significant change in the physical appearance of the mixtures of VCO with each of the excipients upon initial combination. This shows that all the excipients did not exhibit immediate reactivity with VCO. However, triethanolamine, a neutralizing agent commonly used with carbomer 340, demonstrated delayed reaction with VCO as evidenced by the development of yellow coloration after three weeks of temperature stress testing. Both carbomer 340 and triethanolamine were excluded in the formulation development.

Cream preparation. The low-heat process, at least $20^{\circ} \mathrm{C}$ less heating than traditional emulsification, help preserve the heat-labile components of VCO. It is also an alternative green method that significantly reduces energy consumption during heating and cooling stages, and cuts total manufacturing time.

The cold processing method (Method 1) yielded a white, smooth, creamy lotion, while the hot processing methods (Method 2 to Method 4) produced white, soft creams with relatively smooth surfaces. The resulting product from Method I did not meet standard for cream product format. In Method 2, gel formation occurred as the water phase is being added to the oil phase; while in Method 3, water phase was prepared as gel. In both methods, the increased viscosity posed challenge to effective emulsification and homogenization. The gradual thickening of the formulation occurred after the post-emulsification addition of Simulgel ${ }^{\mathrm{TM}} \mathrm{NS}$ (Method 4), which allowed the oil and water phases to be intimately mixed. This was considered to be the most suitable method for product formulation.

Cream formulation. The cream prepared using Simulgel ${ }^{\mathrm{TM}}$ NS and cetyl alcohol was found to exhibit a very slight oil separation in preliminary centrifugation test. To improve the stability of the product, secondary emulsifiers, such as Olivatis-15, Medsmul SEPF and Ceteth-6 were incorporated at different concentrations.

To complement skin $\mathrm{pH}$ and minimize potential irritation during usage, target $\mathrm{pH}$ values for the sample formulations were between 5 and 6.5 [22]. F1 and F3 creams gave pH values below 5 . Preliminary qualification of the trial formulations showed that F2, F4, and F5 were satisfactory in terms of appearance, $\mathrm{pH}$, and stability in the centrifugation test. A decrease in $\mathrm{pH}$ was noted with increasing concentration of the coemulsifiers. All co-emulsifiers were consequently used at $1 \%$ concentration.

Accelerated stability testing. To assess the long-term stability of the prototype formulations under ambient storage conditions, stress testing using thermal and light stresses were applied.

All prototype formulations did not exhibit color changes nor phase separation after four cycles of freeze-thaw test. Thermal stress by temperature cycling is known to accelerate phase separation in emulsions. In general, emulsions that withstand these conditions are likely to be more stable under normal storage conditions [24].

In the elevated temperature tests, the prototype cream formulations maintained a white, smooth cream appearance with mild coconut scent throughout the six-month test period, except for 
prototype F2 which showed softening as early as month 3 . The $\mathrm{pH}$ of the formulations varied within 5.0-5.3 during the storage period (Fig. 1A). There was a general decrease in viscosity (Fig. 1B) and increase in particle size (Fig. 1C) during the storage period. Creaming index was recorded as zero for all time points, since no visible creaming was observed.

Elevated temperature is known to adversely affect the stability of emulsions. Viscosity is an important indicator of emulsion stability, since any variation in droplet size distribution, degree of flocculation, or phase separation, often causes viscosity changes [25]. Being thermodynamically unstable systems, emulsions are expected to undergo changes in certain physico-chemical properties over time. However, rapid changes or major deviations are usually indicative of product instability. The softening and viscosity breakdown of prototype F2 samples in the accelerated stability testing as early as month 3 , show that the formulation with $1 \%$ Olivatis- 15 is not as stable as the other prototypes using equal amounts of Medsmul SEPF (F4) or Ceteth-6 (F5) as coemulsifiers. Among the three, formulation F5 showed greater stability as seen from the minimal change in mean viscosity and particle size values over time. Further, since larger particle sizes tend to remain on the stratum corneum [8], the smaller
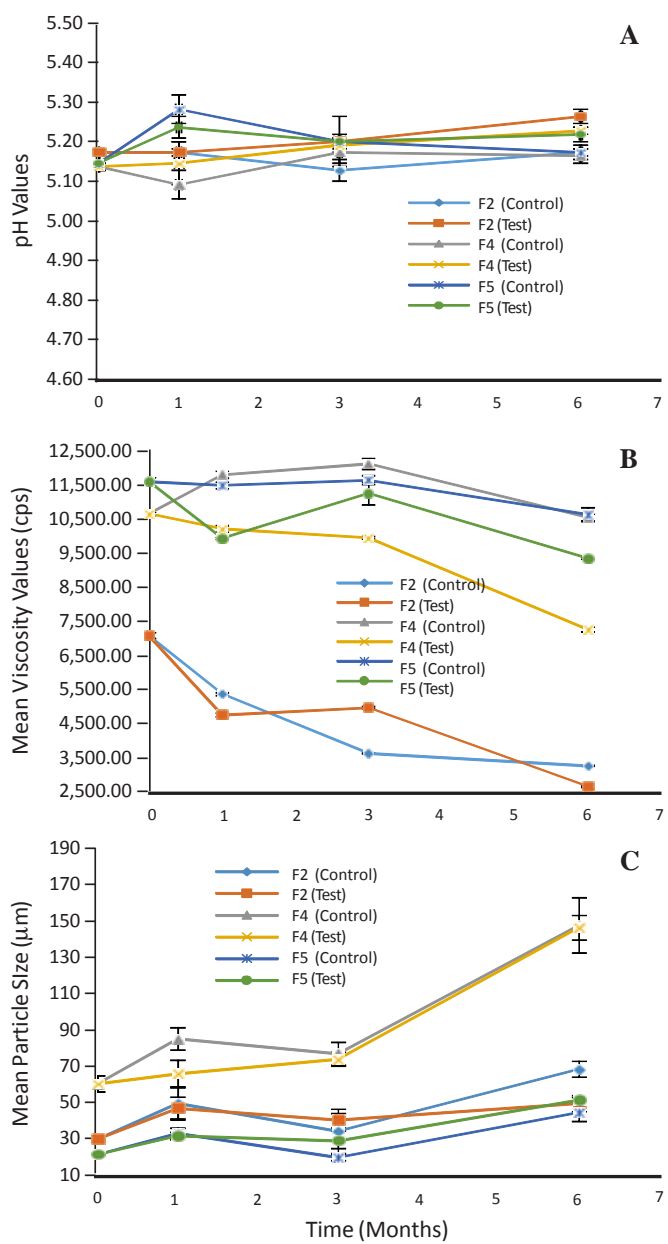

Figure 1. Mean $\mathrm{pH}(\mathrm{A})$, viscosity (B), and particle size (C) values during 6-month accelerated stability testing (Control at $30 \pm 2^{\circ} \mathrm{C}$ and Test at $\left.40 \pm 2^{\circ} \mathrm{C}\right)$.

Table 2. ANOVA comparison of viscosity and particle sizes in 30-day photostability test

\begin{tabular}{|c|c|c|c|c|c|c|}
\hline Groups & $\begin{array}{c}\text { Baseline } \\
\text { (A) }\end{array}$ & $\begin{array}{l}\text { Control } \\
\text { (B) }\end{array}$ & $\begin{array}{l}\text { At } 1 \text { foot } \\
\text { (C) }\end{array}$ & $\begin{array}{l}\text { At } 2 \text { feet } \\
\text { (D) }\end{array}$ & $\begin{array}{c}\text { At } 3 \text { feet } \\
\text { (E) }\end{array}$ & Post Hoc \\
\hline \multicolumn{7}{|l|}{ Viscosity (cps) } \\
\hline F2 & $\begin{array}{r}8800.00 \\
\pm 72.11\end{array}$ & $\begin{array}{l}6473.33 \\
\pm 46.67\end{array}$ & $\begin{array}{r}7333.33 \\
\pm 48.07\end{array}$ & $\begin{array}{r}7246.67 \\
\pm 21.29\end{array}$ & $\begin{array}{r}6806.67 \\
\pm 46.67\end{array}$ & $(\mathrm{~B}=\mathrm{E})<(\mathrm{C}=\mathrm{D})<\mathrm{A}$ \\
\hline $\mathrm{F} 4$ & $\begin{array}{c}13806.67 \\
\pm 17.64 \\
\end{array}$ & $\begin{array}{c}12200 \\
\pm 72.11 \\
\end{array}$ & $\begin{array}{c}12020 \\
\pm 130.13 \\
\end{array}$ & $\begin{array}{c}11986.67 \\
\pm 7.66 \\
\end{array}$ & $\begin{array}{l}11993.33 \\
\pm 116.24 \\
\end{array}$ & $(\mathrm{~B}=\mathrm{C}=\mathrm{D}=\mathrm{E})<\mathrm{A}$ \\
\hline F5 & $\begin{array}{c}12400 \\
\pm 57.74 \\
\end{array}$ & $\begin{array}{r}12293.33 \\
\pm 233.33 \\
\end{array}$ & $\begin{array}{c}12633.33 \\
\pm 81.1 \\
\end{array}$ & $\begin{array}{c}12406.67 \\
\pm 84.8 \\
\end{array}$ & $\begin{array}{l}12653.33 \\
\pm 211.77 \\
\end{array}$ & - \\
\hline \multicolumn{7}{|c|}{ Particle size $\left(\mu \mathrm{m}^{2}\right)$} \\
\hline F2 & $20.93 \pm 2.53$ & $25.70 \pm 3.75$ & $43.03 \pm 5.81$ & $36.37 \pm 5.48$ & $32.70 \pm 2.48$ & $(\mathrm{~A}=\mathrm{B})<(\mathrm{C}=\mathrm{D}=\mathrm{E})$ \\
\hline F4 & $81.3 \pm 6.63$ & $65.6 \pm 5.40$ & $70.87 \pm 2.33$ & $92.33 \pm 2.87$ & $79.4 \pm 5.44$ & $(\mathrm{~B}=\mathrm{C})<(\mathrm{A}=\mathrm{D}=\mathrm{E})$ \\
\hline F5 & $18.57 \pm 3.38$ & $38.97 \pm 3.77$ & $30.23 \pm 3.80$ & $36.6 \pm 2.16$ & $26.10 \pm 3.35$ & $(\mathrm{E}=\mathrm{A})<(\mathrm{B}=\mathrm{C}=\mathrm{D})$ \\
\hline
\end{tabular}

Note: Values expressed as mean \pm SEM, $n=3$. Letters in parentheses under group names refer to the letters used in illustrating statistically significant differences. 
particle sizes of F5 samples favor delivery of VCO active components into deeper skin layers.

In the photostability testing, organoleptic properties of the prototype formulations remained unchanged after one month testing, and $\mathrm{pH}$ values were within $5.00-5.20$ for all samples. The effect of light and varying light intensities on viscosity and particle size of the formulations are summarized in Table 2, which also shows the results of a single-factor analysis of variance (ANOVA) with Tukey's HSD as posttest. Mean viscosity and particle size of prototype F2 were adversely affected by light, and greater increase in particle size was seen with increased light exposure. No lightdependent effect on both mean viscosity and particle size can be concluded from the results obtained for prototypes F4 and F5. Observed changes occurred as a function of time.

Light is known to adversely affect the stability of most product formulations. As in the elevated temperature test, prototype F5 is shown to be most stable in terms of viscosity and particle size.

All the prototype formulations were found to be non-irritating with PII values of 0.5 (F2), 0.0 (F4), and 0.34 (F5). The Draize rabbit test is a standard skin irritation test used by many regulatory agencies. It is a conservative tool

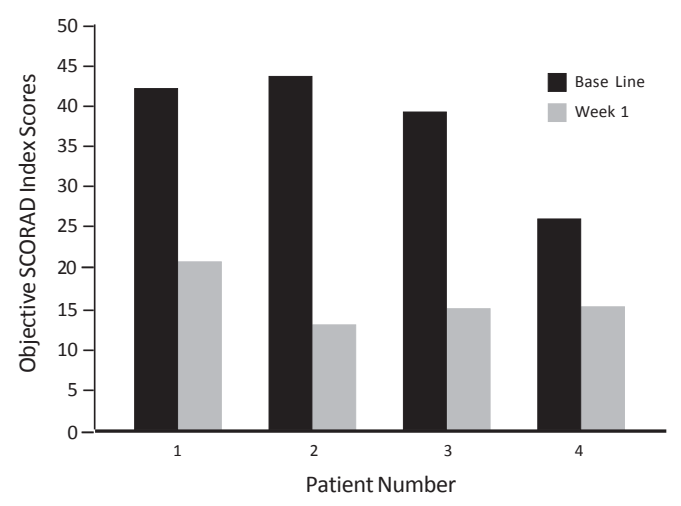

Figure 2. Change in objective SCORAD index scores after 1-week usage test that tends to over-predict the severity of human skin reactions, as many substances which are irritating to the rabbit are actually well-tolerated by the human skin [22]. The non-irritating finding for the three prototype formulations support potential use in diseased skin applications.

Preliminary usage test. The efficacy of prototype formulation $\mathrm{F} 5$ against $\mathrm{AD}$ symptoms was evaluated based on the change in the SCORAD index determined after 1 week. Prototype formulation F5 was well-tolerated by the respondents. There were no reported adverse events. Reduction in individual objective SCORAD index after one week of product usage were noted for all four patients (Fig. 2), and the improvement was found to be significant ( $p=0.013$ ) based on paired t-test analysis. There was no notable change in the subjective SCORAD index post-treatment.

Preliminary usage test results show that twice a day application of the formulated 20\% VCO cream helped improve total eczema and intensity items after only 1 week of product usage. Further, the test product did not induce any adverse reactions even in diseased skin condition for the duration of the study period. These provide strong support for the potential utility of the formulated 20\% VCO cream in the management of symptoms in $\mathrm{AD}$ among pediatric patients.

\section{ConClusion}

VCO is a multifunctional, natural active ingredient with proven clinical effectiveness in alleviating symptoms of AD. The present study provides a skin-compatible, stable cream formulation containing $20 \% \mathrm{w} / \mathrm{w}$ VCO prepared using green method processing with low-heat, post-emulsification addition of an emulsifying polymer. The formulated cream was found to be non-irritating and shows promise as a nonsteroid alternative for the management of symptoms associated with AD. 


\section{ACKNOWLEDGements}

This work was supported by financial grants from the Department of Science and Technology - Accelerated Science and Technology Human Resource Development Program (ASTHRDP), and the Commission on Higher Education (CHED). The authors would also like to acknowledge the University of Santo Tomas Faculty of Pharmacy for the use of its laboratory and animal care facilities.

\section{REFERENCES}

[1] Eichenfield LF, Tom WL, Chamlin SL, Feldman SR, Hanifin JM, Simpson EL, Berger TG, Bergman JN, Cohen DE, Cooper KD, Cordoro KM, Davis DM, Krol A, Margolis DJ, Paller AS, Schwarzenberger K, Silverman RA, Williams HC, Elmers CA, Block J, Harrod CG, Begolka WS, \& Sibury R. Guidelines of care for the management of atopic dermatitis: Section 1. Diagnosis and assessment of atopic dermatitis. Journal of the American Academy of Dermatology 2014; 70(2):338-351.

[2] Valdman-Grinshpoun Y, Ben-Amitai D, \& Zvulunov A. Barrier-restoring therapies in atopic dermatitis: Current approaches and future perspectives. Dermatology Research and Practice 2012; p.1-6. http://dx.doi.org/10.1155/ 2012/923134 (2014 October 27).

[3] Hengge UR, Ruzicka T, Schwartz RA, \& Cork MJ. Adverse effects of topical glucocorticosteroids. Journal of the American Academy of Dermatology 2006; 54(1):1-15.

[4] Boneberger S, Rupec RA, \& Ruzicka T. Complementary therapy for atopic dermatitis and other allergic skin diseases: facts and controversies. Clinics in Dermatology 2010; 28:57-61.

[5] Lee J \& Bielory L. Complementary and alternative interventions in atopic dermatitis. Immunology and Allergy Clinics of North America 2010; 30:411-424.

[6] Yun Y, Kim K, Choi I, \& Ko SG. Topical herbal application in the management of atopic dermatitis: A review of animal studies. Mediators of Inflammation 2014; p.1-8. http://dx.doi.org/ 10.1156/2014/752103 (2018 January 22).
[7] Logeswari P, Kumar VD, Usha PTA, \& Kumar P. In vivo anti- inflammatory effect of Emu Oil (Dromais Novaehollandiae) and virgin coconut oil (Cocos Nucifera) on phorbol ester-induced acute inflammatory model. International Journal of Pharmaceutical Sciences and Research 2014; 5(3):896-899.

[8] Noor NM, Aziz AA, Sarmidi MR, \& Aziz R. The effect of virgin coconut oil loaded solid lipid particles (VCO-SLPS) on skin hydration and skin elasticity. Jurnal Teknologi 2013; 62(1):39-43.

[9] Nevin KG \& Rajamohan T. Effect of topical application of virgin coconut oil on skin components and antioxidant status during dermal wound healing in young rats. Skin Pharmacology and Physiology 2010; 23:290-297.

[10] Padilla-Evangelista MT, Abad-Casintahan F, \& Lopez-Villafuerte $L$. The effect of topical virgin coconut oil on SCORAD index, transepidermal water loss, and skin capacitance in mild to moderate pediatric atopic dermatitis: A randomized, double-blind, clinical trial. International Journal of Dermatology 2014; 53:100-108.

[11] Verallo-Rowell VM, Dillague KM, \& SyahTjundawan BS. Novel antibacterial and emollient effects of coconut and virgin olive oils in adult atopic dermatitis. Dermatitis 2008; 19(6):308315.

[12] Agero AL \& Verallo-Rowell VM. A randomized double-blind controlled trial comparing extra virgin coconut oil with mineral oil as a moisturizer for mild to moderate xerosis. Dermatitis 2004; 15(3):109-116.

[13] Rohman A, Che Man YB, \& Sismindari. Quantitative analysis of virgin coconut oil in cream cosmetics preparations using Fourier transform infrared (FTIR) spectroscopy. Pakistan Journal of Pharmaceutical Sciences 2009; 22(4):415420.

[14] Dimzon IKD, Valde MF, Santos JER, Garrovillas MJM, Dejarme HM, Remollo JMW, \& Dayrit FM. Physicochemical and microbiological parameters in the deterioration of virgin coconut oil. Philippine Journal of Science 2011; 140(1):89-103.

[15] Lemery E, Briancon S, Chevalier Y, Oddos T, Gohier A, Boyron O, \& Bolzinger MA. Surfactants have multi-fold effects on skin barrier function. European Journal of Dermatology 2015; 25(5):424-435. DOI:10.1684/ejd.2015.2587. 
[16] Phaechamud T, Juntawong S, Charoenteeraboon J, \& Chansiri G. Effect of the emulsifier polymers and the concentration of drug on the viscosity and antifungal activity of Clotrimazole cream. Silkaporn University Science \& Technology Journal 2012; 6(2):9-19.

[17] Korac R, Krajisnik D, Savic S, Pantelic I, Jovancic P, Cekic N, \& Milic J. A new class of emulsion systems - Fast inverted o/w emulsions: Formulation approach, physical stability and colloidal structure. Colloids and Surfaces $A$ : Physicochemical and Engineering Aspects 2014; 461:267-278.

[18] ASEAN Guideline on Stability Study of Drug Product (Updated May 2013). http://asean.org (September 25, 2016).

[19] Marquele-Oliveira F, Fonseca YM, de Freitas O, \& Fonseca MJV. Development of topical functionalized formulations added with propolis extract: stability, cutaneous absorption and in vivo studies. International Journal of Pharmaceutics 2007; 342:40-48.

[20] Winuprasith T \& Suphantharika M. Properties and stability of oil-in-water emulsions stabilized by microfibrillated cellulose from mangosteen rind. Food Hydrocolloids 2014; 43:690-699.
[21] Osi MO. Quality Management Control and Assurance of Pharmaceutical Products (Unpublished Handout) 2007.

[22] Benson HAE \& Watkinson AC (Eds.). Transdermal and Topical Drug Delivery: Principles and Practice (1st Edition), pp. 30943 \& 367-407. (John Wiley \& Sons, Inc., 2012).

[23] Carandang EV. Health benefits of virgin coconut oil explained. Philippine Journal of Coconut Studies 2006; 31 (2):1-5.

[24] Sandell E (Ed.). Industrial Aspects of Pharmaceutics, pp. 36-38. (Stockholm: Swedish Pharmaceutical Press, 1993).

[25] Florence AT \& Siepmon J. Modern Pharmaceutics Vol.1 - Basic Principles and Systems $\left(5^{\text {th }}\right.$ Edition), pp. 393-398. (New York: CRC Press, 2010).

[26] Schmitt J, Langan S, Deckert S, Svensson A, von Kobyletzki L, Thomas K, \& Spuls $P$. Assessment of clinical signs of atopic dermatitis: A systematic review and recommendation. The Journal of Allergy and Clinical Immunology 2013; 132(6):1337-1347. 